\title{
The Saphir Gas-Jet and a First Application to an On-Line Separation of Niobium
}

\author{
By YA Nal-Q!*, D. T. Jost, U. Baltensperger and H. W. GAggeler, Paul Scherrer Institut, \\ CH-5303 Würenlingen/Villigen, Switzerland
}

Dedicated to Prof. Hans Rudolf von Gunten on the occasion of his $60^{\text {th }}$ birthday

(Received July 4, 1988)

Saphir reactor / Gas-jet / Fission / Niobium isotopes

\begin{abstract}
A gas-jet system is described which has been installed at one of the external beam lines of the reactor SAPHIR. By means of a Boral chopper between the target chamber and beam line timed production of fission products can be achieved. In a first experiment this gas-jet system was used to develop a continuous and fast separation for short-lived isotopes of niobium with half-lives down to $7 \mathrm{~s}$ using isothermal gas chromatography in quartz columns. As reactive gas $\mathrm{HBr}_{(}(g)$ was used.
\end{abstract}

\section{Introduction}

Gas-jet systems are a standard technique for investigations of nuclear decay properties of short-lived nuclides (see e. g. refs. [1, 2]). They can be applied if the nuclides of interest recoil out of a thin target such as in nuclear fission or in heavy ion reactions. In a thermalisation chamber which is filled with a carrier gas that contains aerosol particles the products are stopped and attached onto the surface of these particles. Mostly nitrogen or noble gases are used as carrier gas and salt particles such as $\mathrm{NaCl}$ or $\mathrm{KCl}$ have proven to be very convenient as aerosol particles [3]. In a continuous mode the reaction products are swept out of the thermalisation chamber and are transported along thin capillaries to counting devices. If separations are needed prior to nuclear spectroscopy, the gas-jet is often coupled to a fast chemical separation apparatus. Most efficiently, such separations are performed continuously. Examples are the SISAK technique which performs solvent extractions in a continuous ultracentrifuge system [4] or on-line gas chromatography for volatile species $[5,6]$. However, also batch-wise working automated HPLC-systems such as the apparatus ARCA [7] have proven to be very useful. In the HELIOS system [8] a gas-jet is coupled to an on-line mass separator.

Despite these manifold gas-jet applications so far only few experiments focused on investigations of the chemical processes in the system itself or used it for purely chemical investigations. For example ZENDEL et al. [9] and RENGAN et al. [10] have used an ethylene/nitrogen gasjet for a chemically selective separation of selenium and tellurium from the bulk of other fission products. On-line high-temperature isothermal gas chromatography was used to test a semiempirical model which describes the adsorption enthalpy of metallic atoms on the surface of metal surfaces [11]. This study was made with the short- lived isotope ${ }^{211 \mathrm{~m}} \mathrm{Pn}$ with a half-life of $24 \mathrm{~s}$ [6]. More recently, gas-jet systems were used to study the chemical properties of heavy elements such as lawrencium [12-14] or element 105 [15].

It is the purpose of this contribution to describe a gas-jet system at the swimming pool reactor SAPHIR designed for chemical studies, especially for investigations of adsorption/desorption processes of fission nuclides onto aerosol particles. Moreover, this gas-jet system can also be used for the development of fast chemical separations. However, it is not suited to the study of nuclear decay properties of fission nuclides since the neutron flux on the target is rather low and, hence, does not permit spectroscopic investigations of nuclides with low fission yields.

In the following we describe our setup which is in . stalled at an external radial beam line of the reactor. To get a well timed production of fission products - a prerequisite for kinetic studies - a chopper is placed between the target and the beam line. Besides a technical description we also present first chemical experiments aimed at a continuous separation of short-lived isotopes of niobium by means of an on-line gas chromatography separation coupled to the SAPHIR gas-jet.

\section{Technical description of the gas-jet}

Figure 1 shows a schematic drawing of the gas-jet setup. In the following paragraphs the individual components are described.

- The gas supply: The carrier gas is supplied from cylinders with a pressure reduction to the desired working pressure of 1 to $5 \mathrm{~atm}$. Solenoid valves are used to disconnect the gas supply from the system. The gas flow is regulated with thermal mass flow controllers in the range of 0.5 to 10 liter per minute (STP). With the two installed mass flow controllers it is also possible to mix two gases in order to perform chemical modifications of the aerosol particles or to add e.g. hydrogen to maintain reducing conditions.

- The aerosol generator: A tubular furnace (HERAEUS) is used to generate the aerosol. Usually $\mathrm{KCl}$ salt in a ceramic boat is placed in the middle of the oven which is heated to $750^{\circ} \mathrm{C}$ (see below). Under these conditions it produces particles in the range of about $0.1 \mu \mathrm{m}$ to $5 \mu \mathrm{m}$.

on leave from the Institute for High Energy Physics, Beijing. 


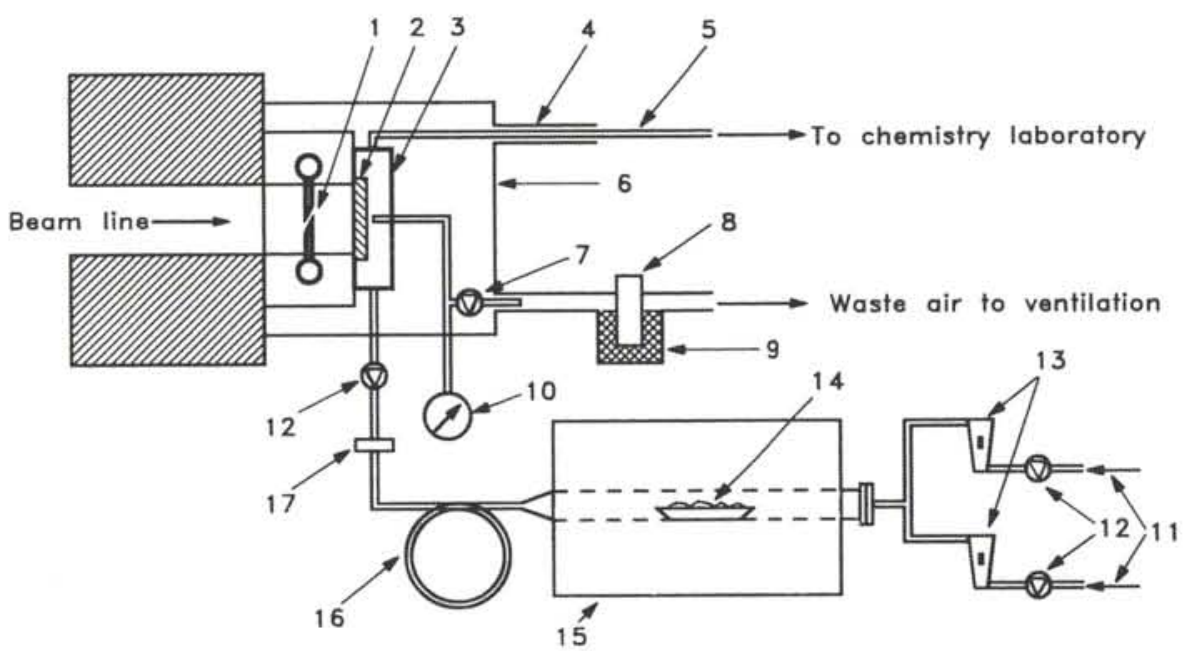

Fig. 1. Schematic of the gas-jet setup at the SAPHIR reactor. 1) chopper, 2) target, 3) target chamber, 4) protective outer tube, 5) transportation capillary, 6) target chamber housing, 7) target chamber relieve valve, 8) activity monitor of waste air with 9) charcoal trap, 10) pressure gauge, 11) gas supply from cylinders, 12) solenoid valves, 13) thermal mass flow controllers, 14) ceramic boat with $\mathrm{KCl}, 15$ ) aerosol generator with tubular furnace, 16) loop of polyethylene tube, 17) sintered glass filter.

These particles are suspended in the carrier gas flowing over the boat thus forming an aerosol. After the aerosol is cooled down to room temperature it is sent through a $5 \mathrm{~m}$ long coil of polyethylene tube and a sintered glass filter to remove very small and very big particles. The aerosol stream is then fed to the target chamber through a polyethylene-tube ( $4 \mathrm{~mm}$ i.d.). An electrically controlled valve at the entrance of the target chamber can be used to interrupt the aerosol flow to the chamber.

- The target chamber: The target chamber made from titanium can accommodate two targets of $50 \mathrm{~mm}$ diameter each, one on the front and one on the back side. Currently one ${ }^{235} \mathrm{U}$ target with an average thickness of $180 \mu \mathrm{g} / \mathrm{cm}^{2}$ electroplated [16] on a $15 \mu \mathrm{m}$ thick aluminum foil is used. Titanium was chosen in order to keep the neutron induced activity of the assembly as low as possible [17]. The $\mathrm{Ti}(\mathrm{n}, \gamma)$ reaction produces only ${ }^{51} \mathrm{Ti}$ with $5.1 \mathrm{~min}$ half-life with a low cross section $(0.2$ barn [18]). The depth of the chamber is sufficient to stop fission products recoiling out from the target in nitrogen ( $p>1.5 \mathrm{~atm}$ ). If helium is used as carrier gas the pressure has to be increased to about $3 \mathrm{~atm}$ or the target has to be covered with a thin aluminum foil $(7 \mu \mathrm{m})$ to reduce the kinetic energy of the recoiling fission products so that they can be stopped in the target chamber. A pressure gauge is connected to the target chamber to control the pressure. The target chamber can be vented through a relieve valve into the waste air stream. The target chamber is housed in a PVC-box kept at a negative pressure relative to the atmosphere in the reactor building.

- The beam line: A radial beam line at the SAPHIR reactor of the Paul Scherrer Institut provides the neutrons for the gas-jet system. The reactor itself is a light water moderated swimming pool type with a thermal power of $10 \mathrm{MW}$. A helium-filled beam line which starts behind a BeO-reflector and extends through the biological shield provides $(4.6 \pm 0.5) \times 10^{6}$ thermal neutrons $/ \mathrm{s} \cdot \mathrm{cm}^{2}$ over a beam spot size of $50 \mathrm{~mm}$ in diameter at the site of the target. From the known fission yield of ${ }^{92} \mathrm{Sr}(34.9 \mathrm{~b}$ [18]) the flux was determined by measuring its activity in a thick aluminum foil placed over the target which collected all recoiling fragments. The plugs of the beam line can be electrically operated and provide the necessary shielding to work at the target chamber site.

- The chopper: The production of the fission nuclides can be precisely timed with a mechanical shutter made of aluminum-boroncarbide. With this Boral shutter of $6 \mathrm{~mm}$ thickness the thermal neutron flux can be reduced by a factor of 100 . The two wings of the shutter open and close within $25 \mathrm{~ms}$.

- The capillary: To transport the activity from the target chamber to the chemistry laboratory over a distance of $130 \mathrm{~m}$ polyethylene capillaries of $2 \mathrm{~mm}$ i.d. are used. For applications with very short-lived nuclides $\left(T_{1 / 2} \sim\right.$ $1 \mathrm{~s})$ a glove box is installed at a distance of $10 \mathrm{~m}$ from the target chamber. To mechanically protect the capillaries and to retain any possible leakage in the system the capillaries are put into an outer tube. A permanent air flow in the outer tube is maintained from the chemistry laboratory to the reactor building.

- The control system: In order to accommodate the changing needs of the experiments a program controlled logic system (PLC PEX, Selectron) is used. This controller is easy to connect to external signal sources and can drive loads such as solenoid valves directly. The controller is programmed by forming boolean expressions with inputs and internal registers and assigning the result to the outputs. It is planned to connect a PC in the chemistry laboratory to this system to give the operator remote control of the gas-jet system.

- Safety and monitoring systems: To reduce the risk of a contamination of the environment several safety mea- 
sures are taken. The waste air from the outer tube of the capillaries and from the target chamber housing is pumped through an activated charcoal filter and then released into the ventilation system of the reactor building. The activity of this charcoal filter is continuously measured. All operating parameters such as gas flow rate, chamber pressure and oven temperature are permanently monitored and compared with upper and lower limits. If any of the limits is reached, an alarm condition is set and an acoustic signal warns the operator. If the fault can not be corrected within $\mathbf{3 0}$ seconds, an interlock is triggered. An interlock is also triggered by one of the following conditions: i) The target chamber pressure changes with more than $5 \mathrm{~atm} / \mathrm{s}$ which would indicate a rupture of the carrier gas feed line or the target chamber, ii) the activity of the charcoal filter of the waste gas stream is too high which would indicate a leak in the target chamber or the capillary, iii) the relieve valve is open or iv) one of the emergency shut-off buttons (e.g. in the chemistry laboratory) is activated. In case of an interlock the chopper and the beam line of the reactor are closed, the gas supply is turned off and the relieve valve of the target chamber is opened.

\section{Transportation yields}

Figure 2 shows measured yields for the transportation of fission products through the $130 \mathrm{~m}$ long capillary from the reactor building to the chemistry laboratory as a function of the oven temperature of the aerosol generator. The carrier gas was helium at a flow rate of $11 / \mathrm{min}$, and $\mathrm{KCl}$ particles were used to form the aerosol. The maximum yield is observed for an oven temperature of $750^{\circ} \mathrm{C}$. This yield was determined by $\gamma$-spectroscopy of the collecting filter paper positioned in front of a HPGe-detector. Collecting and counting time was $30 \mathrm{~min}$. The $100 \%$ value was determined by putting an aluminum foil over the

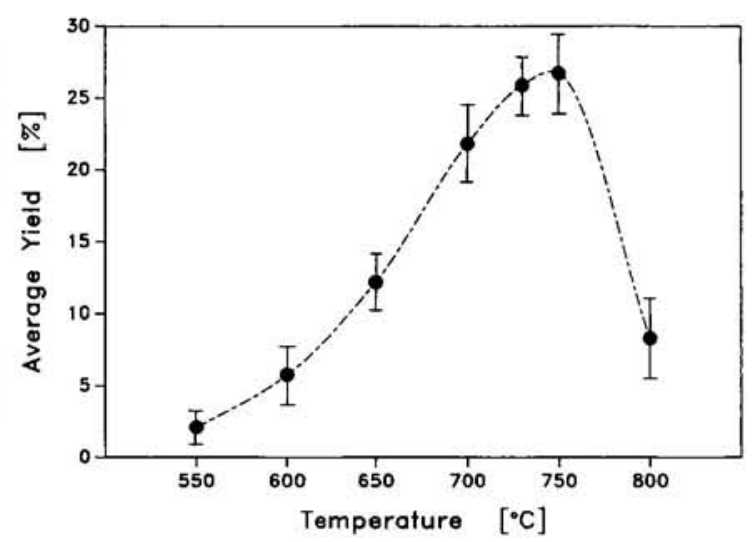

Fig. 2. Transportation yields for non-volatile fission products (isotopes of $\mathrm{Zr}, \mathrm{Nb}, \mathrm{Y}, \mathrm{Sr}, \mathrm{Mo}, \mathrm{Tc}$ ) through a $130 \mathrm{~m}$ long polyethylene capillary ( $2 \mathrm{~mm}$ i.d.) from the reactor building to the chemistry laboratory at a carrier gas flow rate of 1 liter per minute STP helium as a function of the cluster generator temperature.

target and collecting all recoiling fission products. After each measurement the filter paper was changed (see also right part of Fig. 7). The results shown in Fig. 2 represent average yields for non-volatile fission products such as zirconium or niobium which gave within statistical uncertainties identical results. The errors shown represent statistical uncertainties of the $\boldsymbol{\gamma}$-peak analysis only. For volatile elements such as iodine the yields were significantly lower. Identical transportation yields were observed for nitrogen or helium as carrier gas. In the following experiments the oven temperature was kept constant at $750^{\circ} \mathrm{C}$. In routine use it turned out to be necessary to change the $\mathrm{KCl}$ in the ceramic boat and to clean the sintered glass filter roughly once a week in order to assure constant transportation conditions.

A typical $\boldsymbol{\gamma}$-spectrum of such a direct catch is shown in Fig. 3. The main $\gamma$-lines can be attributed to fission products with half-lives longer than about $10 \mathrm{~s}$. The absence of very short-lived isotopes is due to the high transportation time of about $12 \mathrm{~s}$ at a gas flow rate of $21 / \mathrm{min}$

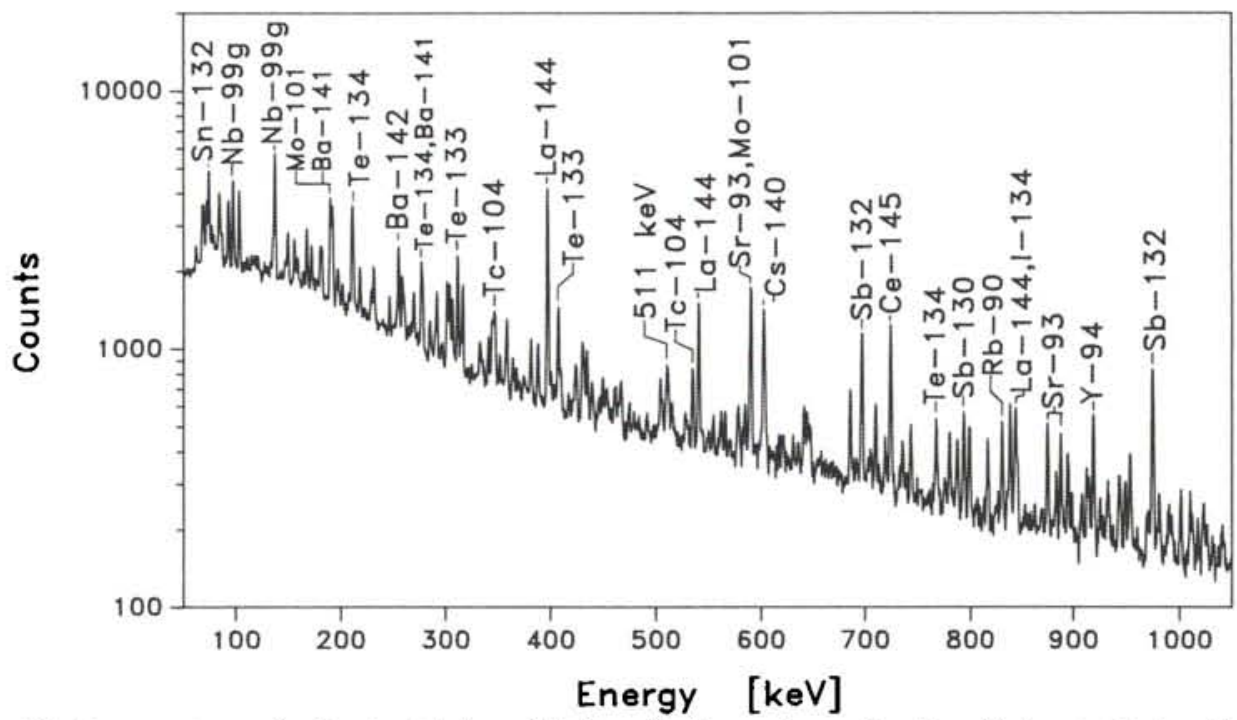

Fig. 3. $\gamma$-spectrum of a direct catch for a $30 \mathrm{~min}$ collection and counting time. Fission products with half-lives from $15 \mathrm{~s}\left({ }^{\left.9{ }^{9} \mathrm{Nb}\right)}\right.$ to $40 \mathrm{~min}\left({ }^{134} \mathrm{Te}\right)$ are observed. 
and the rather long counting time of $30 \mathrm{~min}$. Therefore, if shorter lived nuclides are to be applied, either capillaries smaller in diameter have to be used and counting has to be performed with automated collecting and detection systems (tape, wheel etc.), or the nearby glove box in the reactor building has to be used (see preceding section).

The absolute transportation yield as a function of the gas flow rate was determined by two independent methods. First, the so-called Epiphaniometer [19] was used to determine the yield of ${ }^{211} \mathrm{~Pb}$ transported along the $130 \mathrm{~m}$ long capillary. The Epiphaniometer delivers ${ }^{211} \mathrm{~Pb}$ atoms at a constant rate by the decay of the short-lived isotope ${ }^{219} \mathrm{Rn}$ which itself emanates from a ${ }^{227}$ Ac source. This set-up was put at the position of the target chamber in the reactor building. The corresponding results are shown in Fig. 4. In a second experiment transportation yields of fission products were measured as a function of the carrier gas flow rate (Fig. 5). As already mentioned for Fig. 2, the results shown in Fig. 5 represent average values for non-volatile products. In both cases an increase of the transportation yield is observed with a typical value of about $40 \%$ at a gas flow rate of $21 / \mathrm{min}$. This value is comparable to the $60 \%$ given by Stender et al. [3] using the same aerosol but having a considerably shorter transportation distance of only a few meters.

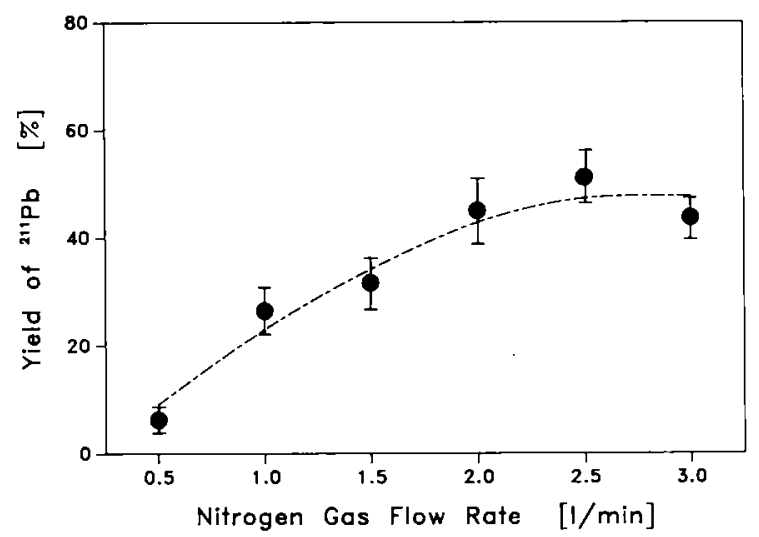

Fig. 4. Transportation yields for ${ }^{211} \mathrm{~Pb}$ along the $130 \mathrm{~m}$ long capillary versus the carrier gas flow rate $\left(\mathrm{N}_{2}\right)$. The yields were measured using the Epiphaniometer (see text).

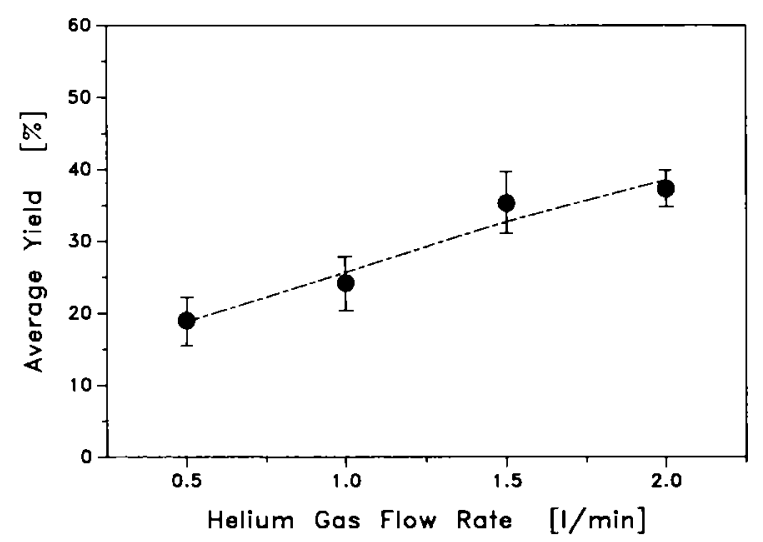

Fig. 5. Transportation yields for non-volatile fission products (see Fig. 3) through the $130 \mathrm{~m}$ long capillary as a function of the carrier gas flow rate $(\mathrm{He})$.

\section{An on-line chemistry for the separation of niobium}

In the course of a renewed interest in investigations of chemical properties of heavy elements continuous and fast separation procedures are needed for trans-actinide elements. This renewed interest stems from predicted relativistic effects for such elements which might change their chemical properties considerably compared to classical predictions based on the periodic table of the elements [20]. Recently the chemical properties of the last actinide element, lawrencium, were studied because calculations $[21,22]$ predict for this element a chemical behavior similar to a $6 p$ element instead of the expected similarity to actinides. However, these investigations did not give any evidence for a $6 p$-behavior of lawrencium so far $[12-14,23]$. An attempt to determine a $p$-behavior of element 104 by means of gas chromatography techniques failed also [24]. In a next series of experiments it is planned to investigate the chemical properties of element 105. First investigations have already been performed [15] which showed that this element like niobium or tantalum [25] can be adsorbed from nitric acid solutions on glass surfaces. In addition, early experiments performed by ZVARA et al. [26, 27] using thermochromatography have indicated that element 105 forms volatile halides such as chlorides or bromides. However, those experiments were hampered by poor statistics (see also [28]).

In the following we describe experiments to optimize a fast and continuous gas chromatography separation for the chemical homologous of element 105 , the fission product niobium. Since the separation procedure is planned to be applied to the nuclide ${ }^{262} 105$ with a halflife of $35 \mathrm{~s}$, all experimental parameters have to be optimized to this time regime. We are therefore using in our study mainly the isotope ${ }^{998} \mathrm{Nb}$ which has a half-life of $15 \mathrm{~s}$. This nuclide is produced in the thermal neutron induced fission of ${ }^{235} \mathrm{U}$ predominantly as decay product of the isobaric precursors ${ }^{99} \mathrm{Sr}\left(T_{1 / 2}=290 \mathrm{~ms}\right),{ }^{99} \mathrm{Y}$ $\left(T_{1 / 2} \leqslant 1 \mathrm{~s}\right)$ and ${ }^{99} \mathrm{Zr}\left(T_{1 / 2}=2.1 \mathrm{~s}\right)$ [18]. The isobar $A=99$ has a chain yield of $6.07 \%$ [18]. In addition, efficient separation of final products from actinide elements. are a prerequisite for a chemical study of trans-actinide elements, since fission counting and $\alpha$-spectroscopy are to be used for their identification. Highest possible decontamination from lanthanide elements or yttrium was therefore tried to achieve in our chemical study. In order to make the identification of niobium isotopes transported with the SAPHIR gas-jet easier, we have covered the ${ }^{235} \mathrm{U}$ target with a $12 \mu \mathrm{m}$ thick aluminum foil. This allows an efficient suppression of the products from the heavy mass peak compared to those from the light one. The former ones having a significantly lower recoil energy when leaving the target are stopped in this foil. A $\boldsymbol{\gamma}$ spectrum from a direct catch obtained in this way is shown in Fig. 6 (top). No products from the heavy mass peak are observed. On the other hand also isotopes not identified in Fig. 3 (e.g. ${ }^{101} \mathrm{Nb}$ ) are detected. 


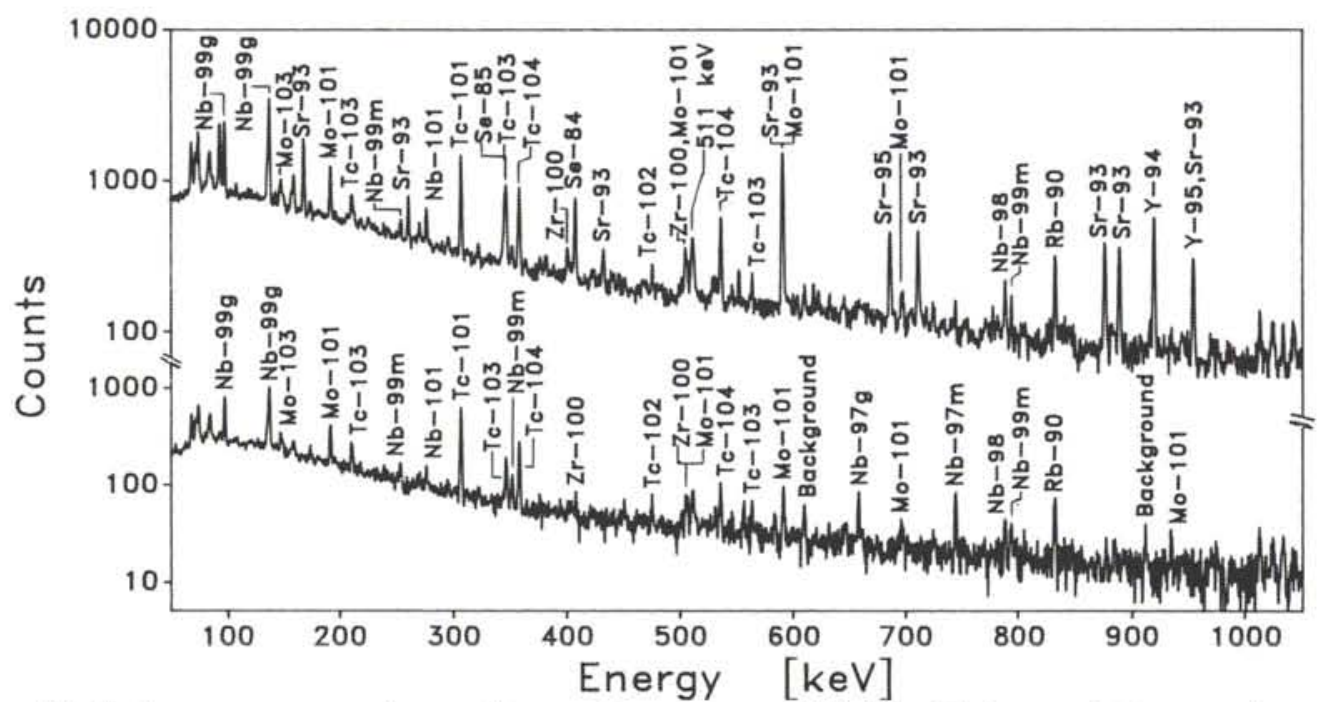

Fig. 6. The upper spectrum shows a direct catch measurement $(30 \mathrm{~min})$ with the target being covered by a $12 \mu \mathrm{m} \mathrm{Al}$ foil. Only light fission products $(A<120)$ are observed. The lower spectrum shows volatile bromides or oxybromides of fission products after a gas chromatography separation. The experimental conditions were: $11 / \mathrm{min}$ STP $\mathrm{He}, 100 \mathrm{ml} / \mathrm{min} \mathrm{HBr}_{(}(\mathrm{g}), 21 / \mathrm{min} \mathrm{N}_{2}$ and $\mathrm{KCl}$ as recluster aerosol, $500^{\circ} \mathrm{C}$ for the isothermal part of the chromatography oven. Note the absence of ${ }^{93,95} \mathrm{Sr}$ and ${ }^{94,95} \mathrm{Y}$.

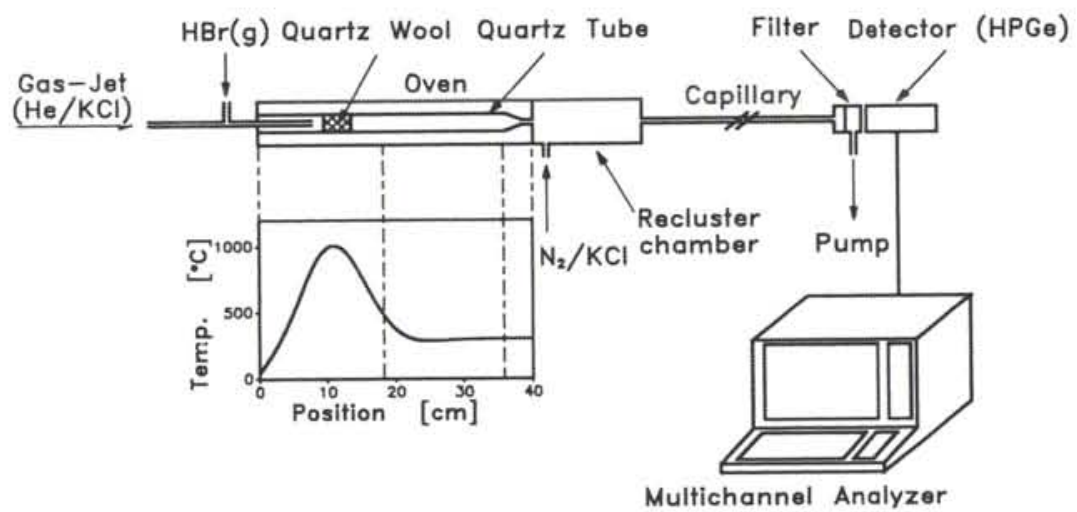

Fig. 7. Gas chromatography apparatus designed for an on-line chemistry of short-lived nuclides. At the entrance of the chromatography tube a reactive gas such as $\mathrm{HBr}_{(\mathrm{g})}$ can be added. The inset shows a typical temperature profile in the chromatography tube. After leaving the capillary shaped endpiece of the chromatography tube the volatile species are cooled down and reattached onto new aerosol particles in a recluster chamber. These products are then transported through a capillary to the collecting filter in front of a HPGe detector.

The on-line gas chromatography was performed with the set-up shown in Fig. 7. It is similar to that used in a previous study aimed at an investigation of the volatility of lawrencium [12]. At the entrance of the chromatography tube (quartz, $6 \mathrm{~mm}$ i.d.) $\mathrm{HBr}_{(}(g)$ is added as reactive gas. Products are stopped on a quartz wool plug inserted into the chromatography tube. This part of the tube is heated to about $1000^{\circ} \mathrm{C}$. Volatile bromides or oxybromides are then transported further along the isothermal second part of the quartz tube. The temperature of the isothermal part can be varied between 100 and $1000^{\circ} \mathrm{C}$. After leaving the column through a capillary shaped endpiece ( $1 \mathrm{~mm}$ i.d.) the volatile species are cooled down in a reclustering chamber (i.d. $6 \mathrm{~cm}$; length $32 \mathrm{~cm}$ ) and are adsorbed onto new $\mathrm{KCl}$ aerosol particles which are continuously injected into this volume with nitrogen as carrier gas. At the exit of this recluster chamber the products attached onto particles are transported further along a few meter long capillary (polyethylene, $2 \mathrm{~mm}$ i. d.) to a collecting glass fiber filter positioned in front of a HPGe detector in the same way as for the direct catch measurements.

Figure 6 (bottom) shows a typical $\gamma$-spectrum obtained in a gas chromatography experiment of $30 \mathrm{~min}$ collecting and counting time. If compared to Fig. 6 (top), the corresponding direct catch measurement, it can be seen that only those products are observed which form volatile bromides or oxybromides [29-32]. Of interest is the good depletion from strontium and yttrium with a factor $\geqslant 50$.

Figure 8 shows the chemical yield for ${ }^{99} \mathrm{gb}$ as a function of the reactive gas $\left(\mathrm{HBr}_{(g)}\right)$ concentration. As chemical yield we define the ratio of $\boldsymbol{\gamma}$-peak areas measured in a direct catch on the filter paper without chemistry as compared to the same counting with the gas chromato. graphy inserted. Obviously, the best conditions for the 


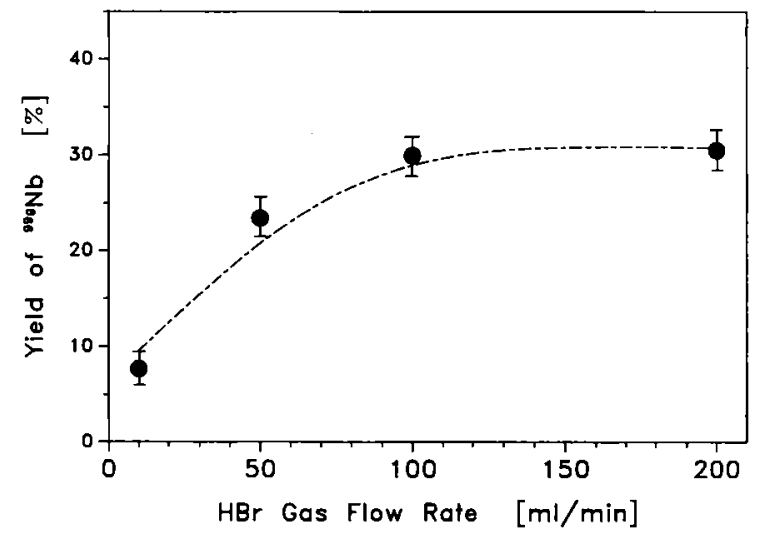

Fig. 8. Yields for ${ }^{99} \mathrm{Nb}$ as a function of the reactive gas $\mathrm{HBr}_{(}(g)$ concentration at the same parameter values as in Fig. 6 (bottom).

separation of the short-lived isotope ${ }^{99} \mathrm{Nb}$ are found at about $100 \mathrm{ml} / \mathrm{min} \operatorname{HBr}_{(g)}$. This yield was found to be nearly independent of the flow rate of the recluster aerosol within a range of 0.5 to $21 / \mathrm{min}$.

In Fig. 9 the yield dependences for the isotopes ${ }^{99 \mathrm{~g}} \mathrm{Nb},{ }^{99 \mathrm{~m}} \mathrm{Nb}\left(T_{1 / 2}=2.6 \mathrm{~m}\right)$ and ${ }^{101} \mathrm{Nb}\left(T_{1 / 2}=7 \mathrm{~s}\right)$ are shown as a function of the temperature of the isothermal part of the oven - at a fixed temperature of $1000^{\circ} \mathrm{C}$ for the quartz wool plug. All yield curves have their maximum at about 300 to $400^{\circ} \mathrm{C}$. At higher temperatures the yields decrease again. This may be caused by a lower yield for the reattachment at higher gas temperatures in the recluster chamber. A similar effect was also found by STEIDEL [32] where volatile bromides of fission products were investigated using $\mathrm{HBr}_{(}(g)$ as reactive gas. In that work highest yields for short-lived isotopes of niobium were found at a temperature of $300^{\circ} \mathrm{C}$ too. In

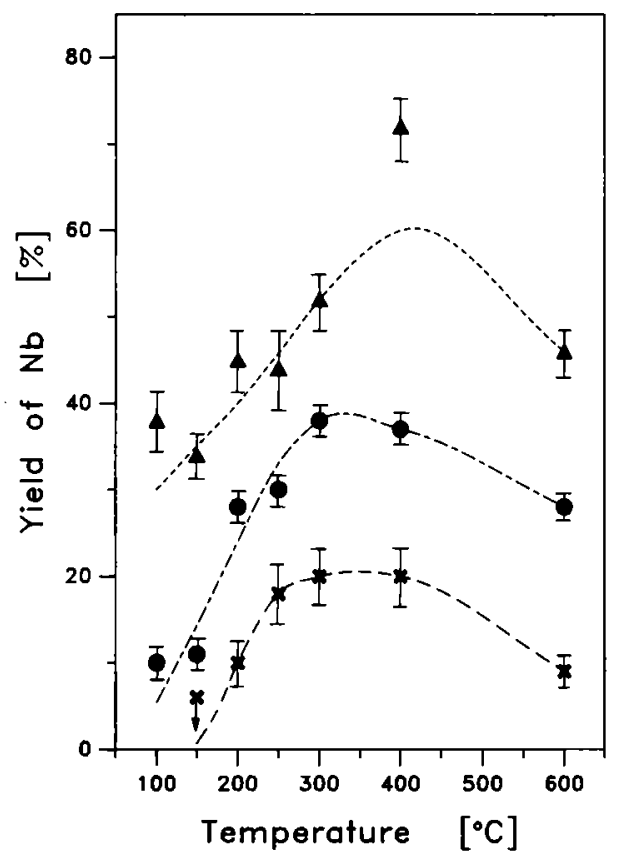

Fig. 9. Yields for ${ }^{101} \mathrm{Nb}\left(\mathrm{X}, T_{1 / 2}=7 \mathrm{~s}\right),{ }^{9 \mathrm{~g}} \mathrm{Nb}\left(\bullet, T_{1 / 2}=15 \mathrm{~s}\right)$ and $99 \mathrm{~m} \mathrm{Nb}\left(\triangleleft, T_{1 / 2}=2.6 \mathrm{~m}\right)$ as a function of the isothermal part of the oven. All other parameters were the same as in Fig. 6 (bottom). off-line thermochromatography experiments with $\mathrm{Br}_{2}$ [33] and $\mathrm{Br}_{2} / \mathrm{BBr}_{3}[29,34]$ as bromating agents, niobium isotopes were found at deposition temperatures on quartz of $125 \pm 30^{\circ} \mathrm{C}[33]$ and $40 \pm 10^{\circ} \mathrm{C}[29,34]$, respectively. Possibly, in the first reference the volatile species observed was $\mathrm{NbOBr}_{3}$ instead of $\mathrm{NbBr}_{5}$, the former one being less volatile $[26,35]$. Since we are using short-lived isotopes in our study with isothermal gas chromatography, it is reasonable that the temperature of $300^{\circ} \mathrm{C}$ for the maximum yield of ${ }^{99} \mathrm{~g} \mathrm{Nb}$ is significantly higher than both temperatures listed above from thermochromatographic studies with long-lived isotopes. From our result, however, we can not decide whether the volatile species separated is $\mathrm{NbBr}_{5}$ or $\mathrm{NbOBr}_{3}$.

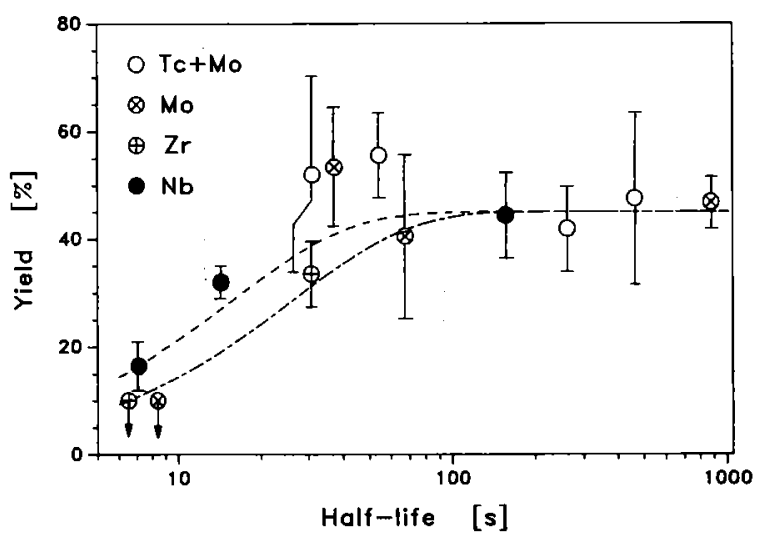

Fig. 10. Yields of volatile bromides or oxy-bromides of different isotopes of Tc, Mo, $\mathrm{Zr}_{\mathbf{r}}$ and $\mathrm{Nb}$ as a function of their half-life. For the experimental parameters see Fig. 6 (bottom). The dashed dotted line represents a homogeneous sweeping-out of the recluster chamber (volume $=910 \mathrm{ml}$ ) at the experimental gas flow condition (3.1 liter per minute STP), adjusted to the yield values of long-lived isotopes. The dashed line shows a fit curve through the niobium data which results in an effective volume of $470 \mathrm{ml}$ (see text).

The observed trend of decreasing maximum yields shown in Fig. 9 with decreasing half-life is mainly caused by the decay during the time required for the reattachment on to new $\mathrm{KCl}$ aerosol particles in the recluster chamber. The kinetics of this process can also be read from Fig. 10 where measured yields for volatile bromides or oxybromides of different isotopes of several fission elements are plotted as a function of their half-life. The temperature of the isothermal section was fixed in this study at $500^{\circ} \mathrm{C}$. The dashed-dotted line shows calculated yields assuming a homogeneous distribution of the volatile species in the recluster chamber, giving an average residence time $t_{r}$ of $18 \mathrm{~s}$ at our gas flow conditions. The curve is adjusted to the measured yields at long half-lives. The dashed line shows a best-fit through the niobium data resulting in an effective residence time in the recluster chamber of about $9 \mathrm{~s}$. This indicates that the volatile products ejecting from the quartz capillary are distributed inhomogeneously in the recluster chamber. In general, yields of $45 \pm 15 \%$ are obtained for nuclides with halflives above about $30 \mathrm{~s}$. For half-lives shorter than $10 \mathrm{~s}$ they drop to values below $20 \%$. 
References

1. MACFAR LANE, R. D., MCHARRIS, W. M. C.: Nuclear Spectroscopy and Reactions, ed. J. CERNY, Vol. A: 244-86, New York § London: Academic Press.

2. Her rmann, G., TrautmanN, N.: Ann. Rev. Nucl. Part. Sci. 32 (1982).

3. STENDER, E., TRAUTMANN, N., HERRMANN, G.: Radiochem. Radioanal. Lett. 42, 291 (1980).

4. TRAUTMANN, N., ARONSON, P. O., BJOERNSTAD, T., KAFFRELL, N., KRALE, E., SHARESTAD, M., SKARNEMAR K, G., STENDER, E.: Inorg. Nucl. Chem. Lett. 11, 729 (1975).

5. DINCKLAGE VON, R. D., SCHREWE, U. J., SCHMIDTOTT, W. D., FEHSE, N. F., BAECHMANN, K.: Nucl. Instrum. Methods 176, 529 (1980).

6. GAEGGELER, H., DORNHOEFER, H., SCHMIDT-OTT, W. D., GREULICH; N., EICHLER, B.: Radiochim. Acta 38, $103(1985)$

7. SCHAEDEL, M., BRUECHLE, W., HAEFNER, B.: Nucl. Instrum. Methods A 264, 308 (1988).

8. MAZUMDAR, A. K., WAGNER, H., KRAEMER, G., WALCHER, W., BRUEGGER, M., STENDER, E., TRAUTMANN, N., LUND, T.: Nucl. Instrum. Methods 174, 183 (1980).

9. ZENDEL, M., STENDER, E., TRAUTMANN, N., HERRMANN, G.: Nucl. Instrum. Methods 153, 149 (1978).

10. RENGAN, K., LIN, J., MASSEY, T. N., ZENDEL, M., MEYER, R. A.: Radiochem. Radioanal. Lett. 50, 385 (1982).

11. EICHLER, B., GAEGGELER, H., ROSSBACH, H., HUEBENER, S.: Radiochim. Acta 38, 131 (1985).

12. JOST, D. T., GAEGGELER, H. W., VOGEL, C., SCHAEDEL, M., JAEGER, E., EICHLER, B., GREGORICH, K. E., HOFFMAN, D. C.: Inorg. Chim. Acta 146, 255 (1988).

13. BRUECHLE, W., SCHAEDEL, M., SCHERER, U. W., KRAT Z, J. V., GREGORICH, K. E., LEE, D., NURMIA, M., CHASTELER, R., HALl, H., HENDERSON, R., HOFFMAN D. C.: Inorg. Chim. Acta 146, 267 (1988).

14. SCHERER, U. W., KRATZ, J. V., SCHAEDEL, M., BRUECH LE, W., GREGORICH, K. E., HENDERSON, R. A., LEE, D., NURMIA, M., HOFFMAN, D. C.: Inorg. Chim. Acta 146, 249 (1988).

15. GREGORICH, K. E., HENDERSON, R. A., LEE, D., NURMIA, M. J., CHASTELER, R. M., HALL, H. L., BENNETT, D. A., GANNETT, C. M., CHADWICK, R. B., LEYBA, D. D., HOFFMAN, D. C., HER RMANN, G.: Radiochim. Acta 43, 223 (1988).
16. PARKER, W., BILDSTEIN, H., GETOFF, N.: Nucl. Instrum. Methods 26, 50 (1964).

17. TRaUtmann, N.: Priv. comm. (1984).

18. SEELMANN-EGGEBERT, W., PFENNIG, G., MUENZEL, H., KLEWE-NEBENIUS, H.: Chart of the Nuclides, 5 th ed., Kernforschungszentrum Karlsruhe 1981.

19. BALTENSPERGER, U., JOST, D., GAEGGELER, H., in: Aerosols, Formation and Reactivity (SCHIKARS KI, W., FISSAN, H. J., FRIEDlandeR, S. K., eds.) Proc. 2nd Int. Aerosol Conf., Berlin, Pergamon Press, Oxford 1986.

20. KELLER, O. L.: Radiochim. Acta 37, 169 (1984).

21. BREWER, L.: High Temp. Sci. 17, 1 (1984).

22. DESCLAUX, J. P., FRICKE, B.: J. Phys. 41,943 (1980).

23. EICHLER, B., HUEBENER, S., GAEGGELER, H. W., JOST, D. T.: Inorg. Chim. Acta 146, 261 (1988).

24. SCHUIKOV, B. L., TSCHUBURKOV, YU. T., TIMOCHIN, S. N., KIM, U. S., ZVARA, I.: Report Joint Institute for Nuclear Research, Dubna, P6-88-109 (in russian) (1988).

25. WEIS, M., AHRENS, H., DENSCHLAG, H. O., FARIWAR, M., HER RMANN, G., TRAUTMANN, N.: Radiochim. Acta 42 (4), 201 (1987).

26. ZVARA, I., BELOV, V., KOROT KIN, YU. S. SHA LAYEVSKY, M. R., SCHEGOLEV, V. A., HUSSONOIS, M., ZAGER, B. A.: Report Joint Institute for Nuclear Research, Dubna, P12-5120 (1970)

27. ZVARA, I., BELOV, V. Z., DOMANOV, V. P., SHALA YEVSKY, M. R.: Sov. Radiochem. 18, 328 (1975).

28. HYDE, E. K., HOFFMAN, D. C., KELLER, O. L.: Radiochim. Acta 42, 57 (1987).

29. ZVARA, I., KELLER, O. L., SILVA, R. J., TARRANT, J. R.: J. Chromatogr. 103, 77 (1975).

30. SILVA, R. J., TRAUTMANN, N., ZENDEL, M., DITTNER, P. F., STENDER, E., AHRENS, H.: Nucl. Instrum. Methods 147, 371 (1977).

31. HICKMANN, U., GREULICH, N., TRAUTMANN, N., GAEGGELER, H., EICHLER, B.: Nucl. Instrum. Methods 174, 507 (1980).

32. STEIDEL, M.: Diploma work, Universität Mainz (1985) (unpublished).

33. TSALAS, S., BAECHMANN, K., HEINLEIN, G.: Radiochim. Acta 29, 271 (1981).

34. SIN, KIM U., TIMOCHIN, S. N., ZVARA, I.: Isotopenpraxis 24, $30(1988)$.

35. RUDOLPH, J., BAECHMANN, K.: Radiochim. Acta 27, 105 (1980). 
